\title{
Eficácia do projeto de criação do Centro de Desportos da Aeronáutica na perspectiva dos stakeholders*
}

\author{
Creation project effectiveness of the Air Force Sports Center in the perspective \\ of stakeholders*
}
Eficacia del proyecto de creación del Centro Deportivo de la Fuerza Aérea desde la perspectiva de las partes interesadas*

Cel Inf Pedro Celso Gagliardi Palermo, Mestre Comissão de Desportos da Aeronáutica - CDA Rio de Janeiro/RJ - Brasil pcgagliardi@gmail.com

\section{RESUMO}

O presente estudo teve por objetivo analisar de que forma os fatores críticos de sucesso, na ótica dos seus stakeholders, impactam na eficácia do projeto de implantação do Centro de Desportos da Aeronáutica (CDAer). Os principais atores envolvidos no processo foram identificados e submetidos a uma investigação por meio de questionário. O instrumento teve por base os fatores críticos de sucesso propostos por Pinto e Slevin (1987). As perguntas foram adaptadas à realidade da proposta, de forma a permitir a análise do grau de importância de cada fator crítico, bem como a eficácia estratégica e tática do projeto. Os resultados demonstraram que a maior parte dos stakeholders entendem que o projeto segue um bom caminho e apresenta uma eficácia estratégica maior que tática, no entanto alguns necessitam receber maior atenção para que suas expectativas sejam atendidas. A metodologia empregada possibilitou ainda apontar os erros potenciais que podem ocorrer no desenvolvimento da implantação do CDAer e que devem ser melhor gerenciados. Como conclusão, sugere-se que seja realizado um claro diagnóstico de seus problemas, principalmente dos relacionados aos clientes, ao pessoal, aos recursos financeiros e à estrutura organizacional, respeitando-se o balanceamento entre a eficácia estratégica e tática da proposta, a fim de atender a todos os interessados.

Palavras-chave: Avaliação de stakeholders. Esporte militar. Gestão esportiva. Eficácia estratégica e tática.

Recebido / Received / Recibido $10 / 09 / 14$
Aceito / Accepted / Aceptado 22/07/15

*Este estudo foi objeto de Trabalho de Conclusão de Curso (TCC) do autor, orientado pelo Prof. Ricardo de Moura, referente ao Curso Avançado em Gestão Esportiva (CAGE), anos 2013-2014, oferecido pelo Instituto Olímpico Brasileiro (IOB), vinculado ao Comitê Olímpico Brasileiro (COB) e à Solidariedade Olímpica. 


\section{ABSTRACT}

This study aimed at analyzing how the critical success factors in the optics of its stakeholders, impact the effectiveness of the deployment project of the Air Force Sports Centre (CDAer). The main actors involved in the process were identified and subjected to an investigation through a questionnaire. The instrument was based on the critical success factors proposed by Pinto and Slevin (1987). The questions were adapted to the reality of the proposal in order to allow analysis of the degree of importance of each critical and strategic effectiveness and project tactics. The results showed that most of the stakeholders understand that the project follows the right track and has a high strategic rather than tactical effectiveness, but some need to receive more attention so that their expectations are met. The methodology enabled even to point out potential errors that may occur in the implementation of the CDAer and that they should be better managed. In conclusion, we suggest that a clear diagnosis of their problems is to be carried out, especially those related to customers, personnel, financial resources and the organizational structure, respecting the balance between the strategic and tactical effectiveness of the proposal in order to cater to all interested parties.

Keywords: Stakeholder assessments. Military sport. Sports management. Strategic and tactical effectiveness.

\section{RESUMEN}

El estudio tuvo por objeto analizar la forma en que los factores críticos de éxito, desde el punto de vista de las partes interesadas, ejercen impacto sobre la eficacia del proyecto de implantación del Centro de Deportes de la Fuerza Aérea (CDAer). Se identificó a los principales actores involucrados en el proceso y se los sometió a una investigación por medio de un cuestionario. El instrumento se basó en los factores críticos de éxito propuestos por Pinto y Slevin (1987). Las preguntas se adaptaron a la realidad de la propuesta con el fin de permitir el análisis del grado de importancia de cada factor crítico, así como la eficacia estratégica y táctica del proyecto. Los resultados mostraron que la mayoría de las partes interesadas consideran que el proyecto está en el buen camino y tiene una eficacia más estratégica que táctica, sin embargo, algunos necesitan recibir más atención para que se satisfagan sus expectativas. La metodología aplicada también permitió señalar posibles errores que pueden ocurrir en el desarrollo de la implantación del CDAer, que deben ser mejor administrados. En conclusión, se sugiere la realización de un diagnóstico claro de sus problemas, especialmente de los relacionados con los clientes, el personal, los recursos financieros y la estructura orgánica, respetando el equilibrio entre la eficacia estratégica y táctica de la propuesta, con el fin de satisfacer a todos los interesados.

Palabras clave: Evaluación de las partes interesadas. Deporte militar. Gestión deportiva. Eficacia estratégica y táctica.

\section{INTRODUÇÃO}

Com o advento dos Jogos Olímpicos em 2016, aliado à realização de diversos eventos esportivos de grande magnitude, o desporto brasileiro, incluído o segmento militar, vem alcançando um novo patamar de desenvolvimento.

Fruto dos V Jogos Mundiais Militares do Conselho Internacional de Esporte Militar (CISM), realizados no Rio de Janeiro em 2011, o desporto militar tem sido visto cada vez mais como um importante desenvolvedor dos talentos esportivos do País, contando em suas fileiras com um importante número de atletas, em nível mundial, de diversas modalidades.

O Comando da Aeronáutica (COMAER), por meio da Comissão de Desportos da Aeronáutica (CDA), vem estudando a transformação dessa unidade em Centro de Desportos da Aeronáutica (CDAer). O projeto visa atender à demanda interna da Aeronáutica de preparo físico-profissional de seus militares para o exercício de suas atividades laborais, mormente as de combate, bem como contribuir com o esforço do País no desenvolvimento do desporto de alto rendimento para participações de atletas brasileiros nos Jogos Olímpicos.

Desde a sua criação, a estrutura física e organizacional da CDA pouco se alterou e, atualmente, não consegue atender a contento a todas as suas demandas. A falta de pessoal qualificado em pesquisa, a inadequada infraestrutura e a dificuldade em atender a todas as Unidades Militares do COMAER impedem que os militares da Força Aérea e os atletas de alto rendimento recebam o devido suporte técnicocientífico e logístico-administrativo que os auxilie nos seus desempenhos.

Ademais, as restrições orçamentárias no investimento de recursos financeiros em ações que 
não sejam as diretamente relacionadas à atividade-fim da Aeronáutica dificultam o avanço da organização em termos estruturais, o que invariavelmente compromete uma atuação abrangente da CDA dentro do COMAER.

Com o advento do momento Olímpico por que passa o país, o Ministério dos Esportes está investindo na reestruturação e modernização das instalações desportivas da CDA, com a construção de modernos equipamentos que serão utilizados pelas equipes estrangeiras durante o período de preparação para os Jogos Olímpicos de 2016.

Os recursos advindos do Ministério dos Esportes, para tal, além do atendimento às demandas Olímpicas, transformarão o campus da CDA em um moderno centro desportivo. Espera-se que esse legado, que ficará sob a responsabilidade do COMAER após o evento, possa ser administrado de forma a atender tanto às necessidades da Aeronáutica quanto às do desporto nacional.

O aporte financeiro do Ministério dos Esportes soluciona a questão financeira para a reestruturação da infraestrutura da Organização, porém faz-se mister entender como os processos de gestão serão levados adiante de forma a atender grupos de interessados (stakeholders) de naturezas distintas.

Conhecer as demandas e satisfazer os stakeholders é a chave para a sobrevivência de uma organização (FREEMAN, 1984). Essa afirmação expressa, de forma direta, a importância dos maiores interessados no sucesso de determinado projeto. E, no caso da criação do CDAer, não é diferente.

O problema, portanto, surge da seguinte inquietação: o CDAer está sendo projetado de forma a atender às demandas esperadas de cada grupo de interessados?

O objetivo geral deste estudo foi analisar de que forma os fatores críticos de sucesso, na ótica dos stakeholders, impactam na eficácia do projeto de implantação do CDAer. Já os objetivos específicos são:

1. identificar os principais stakeholders envolvidos no projeto de criação do CDAer;

2. adequar os fatores críticos de sucesso às especificidades do projeto de criação do CDAer, conforme proposto por Pinto e Slevin (2007);

3. identificar como os stakeholders percebem o grau de importância dos fatores críticos de sucesso (FCS), afetos ao processo de criação do CDAer; e

4. analisar, de acordo com o grau de importância atribuído pelos stakeholders aos FCS, a eficácia do projeto e os seus erros latentes.
O estudo encontra justificativa no aprofundamento da citação de Motta (2012), em que o autor conclui que, a partir do final do século XX, as teorias de administração apresentam um enfoque cada vez mais voltado ao atendimento dos anseios dos consumidores, pois estes direcionam os esforços e recursos de organizações eficazes.

\section{FUNDAMENTAÇÃO TEÓRICA}

Para Santos (2008), a análise dos stakeholders contribui para a formulação de uma estrutura lógica que auxilia a gerência do projeto a identificar estratégias apropriadas e a monitorar eventuais conflitos de interesses.

De acordo com Goldschimidt (2007), as necessidades e expectativas de cada grupo variam, sendo importante que cada um deles perceba que as suas necessidades e expectativas estão sendo satisfeitas.

Para poder atender ou superar tais expectativas, Rabechini (2007) sugere a aplicação de um sistema de gerenciamento dos stakeholders. Nesse sentido, o autor evidencia que gerenciar interessados requer apurar necessidades e implementar ações que visem atender às expectativas, conforme descrito na Figura 1.

Figura 1 - Modelo de gestão dos interessados.

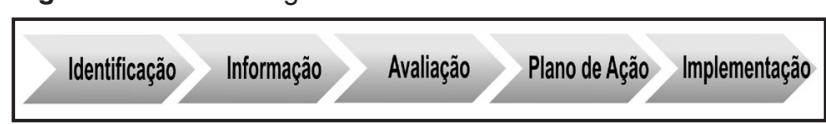

Fonte: Rabechini (2007, p. 26).

Para identificar os interessados, o autor propõe uma subdivisão dos stakeholders em primários e secundários. Os primários são os fornecedores, patrocinadores, credores, ambiente local, gerente de projeto e gerente funcional, contratados e consumidores. Já os secundários são as organizações sociais e políticas, competidores, comunidade, público, turistas, mídia, familiares e ambientalistas.

Santos (2008) orienta que, ao nomear as partes interessadas, não se pode ser tão específico, nem é fundamental que se conectem todos os atores existentes uns com os outros. Portanto, por razões práticas, pode ser útil considerar grupos e subgrupos dentro das organizações, reduzindo a lista inicial àqueles, cujos interesses comuns sejam mais relevantes.

Qualman (1997) ensina que alguns stakeholders detêm maior poder e podem exercer maior influência sobre o desenho, a implementação e os resultados esperados de determinado projeto, categorizando-os conforme a matriz apresentada no Quadro 1. 


\begin{tabular}{|c|c|}
\hline $\begin{array}{c}\text { C- Baixo interesse, Elevado Poder (-/+) } \\
\text { Estes stakeholders podem influenciar os resultados } \\
\text { do projeto, embora as suas prioridades não sejam as } \\
\text { mesmas do projeto. Por serem um risco ou obstáculo, } \\
\text { devem ser monitorados de perto. }\end{array}$ & $\begin{array}{c}\text { A- Elevado Interesse, Elevado Poder }(+/+) \\
\text { São os atores mais importantes. Nesse sentido, todos os } \\
\text { esforços devem ser feitos para que estejam satisfeitos } \\
\text { com o andamento do projeto. }\end{array}$ \\
\hline $\begin{array}{c}\text { D- Baixo Interesse, Baixo Poder (-/-) } \\
\text { Este grupo deve ser monitorado para que se saiba } \\
\text { se haverá mudanças em relação ao seu interesse ou } \\
\text { poder. Apesar de aparentemente apresentar menor } \\
\text { importância, não deve ser negligenciado. }\end{array}$ & $\begin{array}{c}\text { B- Elevado Interesse, Baixo Poder (+/-) } \\
\text { Este grupo é muito útil em fornecer ideias e ajudar } \\
\text { comecessitará de iniciativas especiais para que seus } \\
\text { interesses sejam protegidos. }\end{array}$ \\
\hline
\end{tabular}

Fonte: Adaptado de Qualman (1997).

Robinson et al. (2007), ao se referirem especificamente a stakeholders de organizações esportivas olímpicas (OEO), relatam que normalmente os aspectos financeiros do projeto determinam o grau de interesse e poder (influência) de cada grupo de interessados pelo projeto, porém, não são os únicos. Relatam ainda que aspectos culturais intrínsecos interferem na distribuição dos recursos alocados, o que ajuda a explicar certas decisões tomadas e por que determinados grupos parecem mais importantes que outros.

Segundo o estudo, o aspecto cultural envolve o uso do poder para dirigir, controlar e regular as atividades de uma organização naquilo que se conhece por Governança Corporativa. Tais regras definem o escopo de atuação dos administradores, como são controlados e que decisões devem ser tomadas para a participação de todos os legítimos interessados.

Esse aspecto é particularmente importante para o CDAer, uma vez que o seu projeto de criação envolve instituições inseridas em distintos contextos culturais, resultando em interesses diversos que necessitam ser contemporizados desde o nascedouro do projeto.

Para tanto, deve haver um adequado balanço nas tomadas de decisões, que devem estar respaldadas pelos objetivos traçados pela organização e alinhadas aos resultados esperados pelos seus stakeholders.

Santos (2008) reporta que a análise das partes interessadas contribui desde a fase do desenho até o desenvolvimento da matriz lógica do projeto, ajudando a identificar de forma apropriada a participação de cada uma delas. Além disso, ajuda a antecipar objeções e permite que se proponham ações apropriadas para superá-las. O tipo de abordagem na gestão do relacionamento com os atores vai depender, entre outros aspectos, da situação, do grau de dificuldade na obtenção de informações e da facilidade no alcance dos atores envolvidos. Estes, segundo o autor, são considerados fatores críticos na escolha da abordagem de análise dos stakeholders.

Normalmente, um projeto é conduzido por um gerente de projetos que, em última instância, é um dos principais responsáveis pelo seu sucesso. No entanto Slevin e Pinto (1987) dedicam grande importância tanto aos gestores, quanto aos demais interessados, salientando que todos os grupos devem regularmente avaliar o andamento do mesmo e, mais que isso, oferecer percepções sobre vários pontos de vista, reforçando os objetivos e emprestando suas impressões sobre a satisfação de suas expectativas.

Os autores propõem 10 (dez) fatores críticos, que podem ser utilizados na investigação e identificação dos riscos potenciais que interferem no sucesso de qualquer projeto, a saber: Missão, Apoio da Alta Administração, Planejamento, Cliente Consultor, Pessoal, Questões Técnicas, Cliente Aceite, Monitoramento, Comunicação e Conciliação. Os três primeiros fatores críticos - Missão, Apoio da Alta Administração e Planejamento - referem-se às estratégias do projeto, ou seja, ao processo de estabelecimento dos objetivos gerais e o que se pretende com eles. Os demais fatores estão mais relacionados aos aspectos táticos, à ação e ao alcance dos objetivos estabelecidos.

Os autores estabelecem ainda 4 (quatro) fases de um projeto durante o seu ciclo de vida: Concepção, Planejamento, Execução e Término. O nível de esforço da equipe e dos stakeholders é crescente desde a Concepção, passando pelo Planejamento e à Execução do projeto. Nesta terceira fase, alcança o seu ápice para, então, decrescer até a fase de Término. Nos dois primeiros estágios - Concepção e Planejamento -, prevalece a estratégia; nas fases de Execução e Término, a tática. Ao final, ambos os aspectos - estratégicos e táticos - estão praticamente no mesmo nível de importância para o sucesso do projeto (SLEVIN; PINTO, 1987).

Os autores concluem o seguinte: a) o uso do modelo de múltiplos fatores é viável quando se pretende entender o caminho que se está seguindo em um determinado projeto; b) esses fatores devem ser pensados estrategicamente desde o início, uma vez que são muito sensíveis para o sucesso da implementação pretendida; c) a gerência do projeto e seus stakeholders devem desenvolver ações estratégicas e táticas, atentando para o balanceamento e a transição de importância entre os fatores críticos que os definem; e d) à medida que o ciclo de vida avança, deve-se pensar e agir taticamente.

Além dos fatores financeiros e culturais citados, outras variáveis de cunho mercadológico também afetam o planejamento estratégico e interferem na gestão de uma OEO. 
De acordo com Rocha e Bastos (2011), a gestão de uma OEO tem como atividade principal a produção e o marketing de serviços relacionados ao esporte. A produção preocupa-se com a transformação da matéria-prima em produto final, enquanto o marketing esportivo ocupa-se de todas as atividades designadas para atender a necessidades e desejos de consumidores do esporte através de processos de troca (MULLIN; HARDY; SUTTON, 2007 apud ROCHA; BASTOS, 2011).

Motta (2012) diz que o produto de uma arena esportiva, assim como será o CDAer após concluídas as obras de infraestrutura, caracteriza-se por aspectos tangíveis e intangíveis, a saber:

- tangíveis: instalações e equipamentos, mobiliário, equipe funcional;

- intangíveis: apelos emocionais, aspectos culturais, valores institucionais.

No caso do CDAer, o investimento de recursos públicos em uma instalação militar é visto como garantia de que os recursos estão sendo empregados em uma organização de credibilidade. Toledo (2013) refere que as Forças Armadas estão entre as instituições que detêm um dos mais altos índices de confiança social. Nesse sentido, ainda que os recursos para modernização das instalações esportivas (produto tangível) sejam financiados pelo Ministério dos Esportes, os valores cívicos e institucionais, aliados aos aspectos culturais (produto intangível) das Organizações Militares, encerram o entendimento de que, de alguma forma, quer seja pela conquista de medalhas, ou pelo melhor preparo dos militares na defesa da nação, haverá, invariavelmente, um retorno justificável para a sociedade.

De acordo com Rabechini (2007), o sucesso ou fracasso da implementação de um projeto depende de um correto entendimento dos conceitos e dos requisitos de gerenciamento do mesmo, principalmente quando se busca adequar anseios de parceiros a interesses aparentemente difusos. Nesse caso, deve-se identificar e maximizar a sinergia potencial existente entre eles de forma a favorecer a adoção de um planejamento amplo capaz de gerar resultados concretos aos envolvidos.

Isso posto, ganha importância a aplicação de um método de investigação e de controle dos fatores críticos de sucesso, à medida que, por meio de sua correta compreensão, podese antecipar a identificação de erros potenciais e propor as devidas recomendações e correções de rumo.

\section{METODOLOGIA}

Para a identificação dos stakeholders, seguiu-se o método proposto por Rabechini (2007) e a técnica de dinâmica de grupo, conhecida como brainstorming, entre os Oficiais da CDA que elaboraram a Proposta de Criação do CDAer (BRASIL, 2015). Após a determinação dos atores primários e secundários, seguiu-se a determinação dos 4 (quatro) principais grupos, assim descritos:
G1 - Oficiais Generais membros do Alto Comando da Aeronáutica, Secretário Nacional de Esportes de Alto Rendimento do Ministério dos Esportes, Presidente da CDA e Presidente da Comissão Desportiva Militar do Brasil (CDMB).

G2 - Oficiais Superiores do Departamento de Ensino da Aeronáutica, do Estado-Maior da Aeronáutica, do Comando Geral de Pessoal, do Centro de Controle Interno da Aeronáutica, além dos gestores do projeto da CDA.

G3 - Presidentes ou Diretores Técnicos das Organizações Esportivas civis e militares, com as quais a CDA tem relacionamento direto, Assessores da Secretaria de Esportes de Alto Rendimento do Ministério dos Esportes e membros do Comitê Olímpico Brasileiro.

G4-Militares de carreira da Aeronáutica, atletas civis e militares e Seções de Educação Física das Escolas Militares.

Neste estudo, foram adaptados os fatores críticos propostos por Slevin e Pinto (1987) e adotada a sugestão de Santos (2008), de que a análise das partes interessadas vai depender da situação, do grau de dificuldade na obtenção de informações e da facilidade no alcance dos atores envolvidos.

Para a confecção do questionário, considerou-se o conteúdo do documento intitulado Proposta de Criação do CDAer (BRASIL, 2015). Com base nesse documento, foram propostas 45 (quarenta e cinco) questões, divididas em 9 (nove) blocos de 5 (cinco) perguntas. As opções de respostas possíveis variaram, conforme escala de Likert, de 1 (um) a 7 (sete), em que 1 (um) significa 'Não concordo absolutamente' e 7 (sete), 'Concordo Fortemente'.

O questionário foi validado por meio de um préteste, conforme orientado por Marconi e Lakatos (2003, p. 203), passando pela avaliação de 4 (quatro) Oficiais Superiores e 1 (um) Diretor Técnico de Confederação Desportiva, que sugeriram as adaptações necessárias para o perfeito entendimento do mesmo.

O instrumento foi enviado a 66 (sessenta e seis) stakeholders, representantes dos 4 (quatro) grupos identificados. Como critério de inclusão do estudo, optou-se por selecionar aqueles que possuíam familiaridade com a proposta de criação do CDAer, mesmo que com diferentes graus de profundidade. Como o interesse e o poder de cada grupo de stakeholders é diferente, foram selecionadas as questões endereçadas a cada um deles, de forma que tivessem de responder somente às que lhes eram mais afetas.

O Quadro 2 apresenta a distribuição das questões por grupo de atores envolvidos, bem como a quantidade de questionários distribuídos. 
Quadro 2 - Distribuição das perguntas por grupo de stakeholders.

\begin{tabular}{|c|c|c|c|c|}
\hline $\begin{array}{c}\text { Questões Relativas aos } \\
\text { Fatores Críticos }\end{array}$ & G1 & G2 & G3 & G4 \\
\hline $\begin{array}{l}\text { FCE } 1 \text { - Objetivos Centrais do } \\
\text { CDAer }\end{array}$ & $\mathrm{x}$ & $\mathrm{x}$ & $\mathrm{x}$ & $\mathrm{x}$ \\
\hline $\begin{array}{c}\text { FCE } 2 \text { - Alta Administração do } \\
\text { COMAER } \\
\end{array}$ & $\mathrm{x}$ & $\mathrm{x}$ & & \\
\hline $\begin{array}{c}\text { FCT } 3 \text { - Estrutura } \\
\text { Organizacional Proposta }\end{array}$ & $\mathrm{x}$ & $\mathrm{x}$ & $\mathrm{x}$ & $\mathrm{x}$ \\
\hline $\begin{array}{c}\text { FCT } 4 \text { - Questões Relacionadas } \\
\text { ao Pessoal } \\
\end{array}$ & $\mathrm{x}$ & $\mathrm{x}$ & & \\
\hline $\begin{array}{c}\text { FCT } 5 \text { - Recursos Financeiros } \\
\text { para Vida Vegetativa }\end{array}$ & $\mathrm{x}$ & $\mathrm{x}$ & & \\
\hline FCE 6 - Planejamento & & $\mathrm{x}$ & & \\
\hline FCT 7 - Infraestrutura & & $\mathrm{x}$ & $\mathrm{x}$ & $\mathrm{x}$ \\
\hline $\begin{array}{l}\text { FCT } 8 \text { - Cliente (potenciais } \\
\text { beneficiários do CDAer) }\end{array}$ & & $\mathrm{x}$ & $\mathrm{x}$ & $\mathrm{x}$ \\
\hline FCE 9 - Apoio ao Projeto & & $\mathrm{x}$ & $\mathrm{x}$ & $\mathrm{x}$ \\
\hline $\mathrm{N}^{\circ}$ de questionários enviados & 6 & 11 & 21 & 28 \\
\hline $\begin{array}{l}\mathrm{N}^{\circ} \text { e percentual de } \\
\text { questionários devolvidos }\end{array}$ & $\begin{array}{c}1 \\
(16 \%)\end{array}$ & $\begin{array}{c}6 \\
(54 \%)\end{array}$ & $\begin{array}{c}13 \\
(61 \%)\end{array}$ & $\begin{array}{c}14 \\
(50 \%)\end{array}$ \\
\hline
\end{tabular}

Legenda: FCE - Fator Crítico Estratégico; FCT - Fator Crítico Tático. Fonte: $\mathrm{O}$ autor.

Uma vez devolvidos os questionários, foi realizada a identificação das modas e dos valores mínimos de cada resposta por fator crítico e por grupo de stakeholders. A moda foi utilizada por ser uma medida de tendência central que representa o valor de maior frequência. Os valores mínimos, por sua vez, representam as opiniões mais negativas, que, uma vez conhecidas, poderão agregar valor na proposição de recomendações para eventuais correções de rumo do projeto.

Feito isso, o passo seguinte consistiu em realizar-se o somatório das modas e valores mínimos e correlacionálo aos escores percentuais (Quadro 3), a partir de uma adaptação da proposta de Pinto e Slevin (1998 apud RABECHINI, 2007).

Quadro 3 - Escores percentuais dos fatores críticos de sucesso.

\begin{tabular}{|c|c|c|c|c|c|c|c|c|c|}
\hline Percentual & FCE & FCE & FCT & FCT & FCT & FCE & FCT & FCT & FCE \\
& $\mathbf{2}$ & $\mathbf{2}$ & $\mathbf{3}$ & $\mathbf{4}$ & $\mathbf{5}$ & $\mathbf{6}$ & $\mathbf{7}$ & $\mathbf{8}$ & $\mathbf{9}$ \\
\hline $100 \%$ & 35 & 35 & 35 & 35 & 35 & 35 & 35 & 35 & 35 \\
\hline $90 \%$ & 34 & 34 & 34 & 32 & 32 & 33 & 32 & 34 & 34 \\
\hline $80 \%$ & 33 & 32 & 32 & 30 & 30 & 31 & 30 & 33 & 32 \\
\hline $70 \%$ & 32 & 30 & 31 & 28 & 28 & 30 & 28 & 32 & 30 \\
\hline $60 \%$ & 31 & 28 & 30 & 27 & 27 & 28 & 27 & 31 & 28 \\
\hline $50 \%$ & 30 & 27 & 29 & 24 & 24 & 27 & 24 & 30 & 27 \\
\hline $40 \%$ & 29 & 25 & 27 & 22 & 22 & 26 & 22 & 29 & 25 \\
\hline $30 \%$ & 28 & 23 & 26 & 20 & 20 & 24 & 20 & 27 & 23 \\
\hline $20 \%$ & 26 & 20 & 24 & 18 & 18 & 21 & 18 & 25 & 20 \\
\hline $10 \%$ & 25 & 17 & 21 & 14 & 14 & 16 & 14 & 22 & 17 \\
\hline $0 \%$ & 7 & 6 & 8 & 5 & 5 & 5 & 5 & 7 & 6 \\
\hline
\end{tabular}

Fonte: Adaptado de Pinto e Slevin (1998 apud RABECHINI, 2007, p. 54).
Fatores que apresentam bom desempenho são aqueles com pontuação entre $80 \%$ e $100 \%$. Fatores situados entre $50 \%$ e $80 \%$ merecem atenção e os com pontuações menores que $50 \%$ são considerados críticos (PINTO \& SLEVIN, 1998 apud RABECHINI, 2007).

Seguindo-se a metodologia de Slevin e Pinto (1987), os dados permitiram identificar os erros potenciais que $\mathrm{O}$ projeto pode apresentar, segundo a ótica de cada grupo de interessados, e, partir deles, propor recomendações. A identificação dos erros seguiu a Matriz de Eficácia Estratégica e Tática, constante do Quadro 4.

Quadro 4: Matriz de eficácia estratégica e tática de um projeto.

\begin{tabular}{|c|c|c|c|}
\hline \multirow{6}{*}{ 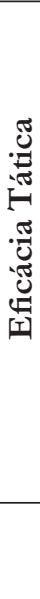 } & Alta & $\begin{array}{l}\text { Potencial para erros } \\
\text { dos tipos II e III } \\
\text { Alta aceitação e uso } \\
\text { incorreto. }\end{array}$ & $\begin{array}{c}\text { Alto } \\
\text { potencial para } \\
\text { implementação com } \\
\text { sucesso do projeto. }\end{array}$ \\
\hline & & 2 & 1 \\
\hline & & 3 & 4 \\
\hline & Baixa & $\begin{array}{l}\text { Alto potencial } \\
\text { para falha na } \\
\text { implementação do } \\
\text { projeto. }\end{array}$ & $\begin{array}{c}\text { Potencial para } \\
\text { ocorrência de erros } \\
\text { dos tipos I e IV. Baixa } \\
\text { aceitação e baixo uso. }\end{array}$ \\
\hline & & Baixa & Alta \\
\hline & & \multicolumn{2}{|c|}{ Eficácia Estratégica } \\
\hline
\end{tabular}

Fonte: Slevin e Pinto (1987, p. 37).

De acordo com a matriz, existem 4 (quatro) tipos de combinações decorrentes do desempenho dos gestores no balanceamento entre estratégia e tática durante o processo. O erro do tipo I ocorre quando há um inadequado nível de atividades táticas desenvolvidas e poucas ações em favor do projeto são implementadas. O erro do tipo II acontece quando se adota uma ação que não deveria ter sido aplicada. O erro do tipo III aparece quando se resolve o problema errado por meio de uma ação efetiva. Por fim, o erro do tipo IV é aquele em que se tem conhecimento das ações que devem ser perpetuadas, mas que, por alguma razão, não são.

A limitação central desse estudo é que os respondentes expressaram suas percepções pessoais sobre o assunto, sem necessariamente representarem a posição oficial das instituições de que fazem parte. Outra limitação refere-se à baixa participação dos membros do G1.

\section{RESULTADOS E DISCUSSÃO}

A Tabela 1 apresenta os resultados da moda e do percentual de sucesso por fator crítico, por grupo estudado. 
Tabela 1 - Moda e percentual de sucesso por grupo.

\begin{tabular}{|c|c|c|c|c|c|c|c|c|c|c|c|c|c|c|c|c|}
\hline \multirow{3}{*}{$\begin{array}{l}\text { Fatores } \\
\text { Críticos }\end{array}$} & \multicolumn{4}{|c|}{ G1 $(n=1)$} & \multicolumn{4}{|c|}{ G2 $(n=6)$} & \multicolumn{4}{|c|}{ G3 $(n=13)$} & \multicolumn{4}{|c|}{ G4 $(n=14)$} \\
\hline & Moda & $\%$ & Mínimo & $\%$ & Moda & $\%$ & Mínimo & $\%$ & Moda & $\%$ & Mínimo & $\%$ & Moda & $\%$ & Mínimo & $\%$ \\
\hline & & Sucesso & & Sucesso & & Sucesso & & Sucesso & & Sucesso & & Sucesso & & Sucesso & & Sucesso \\
\hline FCE 1 & 29 & $40 \%$ & 29 & $40 \%$ & 33 & $80 \%$ & 27 & $25 \%$ & 31 & $60 \%$ & 21 & $8 \%$ & 32 & $70 \%$ & 14 & $4 \%$ \\
\hline FCE 2 & 35 & $100 \%$ & 35 & $100 \%$ & 30 & $70 \%$ & 22 & $25 \%$ & & & & & & & & \\
\hline FCT 3 & 35 & $100 \%$ & 35 & $100 \%$ & 33 & $85 \%$ & 25 & $25 \%$ & 33 & $85 \%$ & 19 & $9 \%$ & 34 & $90 \%$ & 17 & $8 \%$ \\
\hline FCT 4 & 30 & $80 \%$ & 30 & $80 \%$ & 29 & $75 \%$ & 24 & $50 \%$ & & & & & & & & \\
\hline FCT 5 & 33 & $95 \%$ & 33 & $95 \%$ & 30 & $80 \%$ & 25 & $54 \%$ & & & & & & & & \\
\hline FCE 6 & 26 & $60 \%$ & 26 & $60 \%$ & 27 & $60 \%$ & 22 & $40 \%$ & & & & & & & & \\
\hline FCT 7 & 33 & $95 \%$ & 33 & $95 \%$ & 33 & $94 \%$ & 23 & $45 \%$ & 30 & $80 \%$ & 14 & $10 \%$ & 23 & $45 \%$ & 13 & $9 \%$ \\
\hline FCT 8 & 32 & $70 \%$ & 32 & $70 \%$ & 32 & $70 \%$ & 13 & $5 \%$ & 25 & $20 \%$ & 5 & $0 \%$ & 13 & $5 \%$ & 7 & $0 \%$ \\
\hline FCE 9 & 35 & $100 \%$ & 35 & $100 \%$ & 35 & $100 \%$ & 35 & $100 \%$ & 35 & $100 \%$ & 16 & $9 \%$ & 35 & $100 \%$ & 20 & $20 \%$ \\
\hline
\end{tabular}

Legenda: FCE - Fator Crítico de cunho Estratégico; FCT - Fator Crítico de cunho Tático.

\section{Fonte: $\mathrm{O}$ autor.}

Os dados mostram que os grupos de stakeholders estudados eram heterogêneos. A análise do G1 ficou prejudicada, pois somente 1 (um), entre 6 (seis) stakeholders do grupo, enviou resposta. Apesar de ter sido bastante receptivo ao projeto, o G2 considerou o FCE 1 (Objetivos) abaixo de $50 \%$ e os FCE 6 (Planejamento) e FCT 8 (Clientes) entre $50 \%$ e $80 \%$. Para ele, todos os demais FCE e FCT apresentam bom desempenho (acima de 80\%).

O G2 é o único grupo em que os percentuais das modas de todos os fatores críticos estão acima de 50\%. Os fatores FCE 2 (Alta Administração), FCT 4 (Pessoal), FCE 6 (Planejamento) e FCT 8 (Clientes) apresentam valores entre $50 \%$ e $80 \%$, necessitando de maior atenção por parte dos gestores do projeto.

O G3 apresenta os fatores FCT 3 (Estratégica Organizacional), FCT 7 (Infraestrutura) e FCT 9 (Apoio ao Projeto) acima de 80\%. No entanto o FCE 1 (Objetivos), com $60 \%$, necessita de maior atenção, enquanto o FCT 8 (Clientes), com $20 \%$, está classificado como crítico.

O G4 apresenta resultados similares ao G3. Os fatores FCT 3 e FCE 9 estão acima de 80\%, enquanto FCE 1 (Objetivos), com 70\%, necessita de maior atenção e FCT 7 (Infraestrutura), com 45\%, e FCT 8 (clientes), com somente $5 \%$, apresentam resultados críticos.

Somente 2 (dois) fatores críticos apresentam boas opiniões entre os 4 (quatro) grupos: FCT 3 (Estrutura Organizacional) e FCE 9 (Apoio ao Projeto). Já os fatores que apresentam as maiores diferenças de opinião são o FCE 1 (Objetivos), FCT 7 (Infraestrutura), o que demonstra grande heterogeneidade entre os grupos.

O G1, ainda que contando com somente a opinião de 1 (um) stakeholder, mostra evidências de não haver entendido de forma clara os objetivos do CDAer (FCE 1). Isso requer uma intervenção imediata por parte dos gestores, uma vez que representantes desse grupo possuem elevado poder e suas decisões interferem de forma fundamental no projeto.
Já os representantes do G4 temem que os aspectos relacionados à manutenção e infraestrutura (FCT 7) não sejam adequadamente monitorados. Essa percepção do G4 defronta-se com as opiniões dos stakeholders dos grupos G1, G2 e G3, que apontam, repectivamente, 95\%, 94\% e 80\% de sucesso. A discrepância de opiniões pode ser explicada por uma inadequada comunicação dos gestores com os atletas e usuários dos campos esportivos (representantes do G4) e aponta um desbalanceamento no monitoramento entre os grupos de interessados.

Essa assertiva encontra respaldo quando se analisam os resultados do FCT 8 (Clientes), fator que apresentou o pior desempenho nos G2, G3 e G4, com os dois últimos grupos demonstrando estarem gravemente desinformados (20\% e 5\%). Esses números são indicativos de que seus membros se sentem excluídos do processo de construção do CDAer. O próprio grupo de gestores (G2) aponta somente $70 \%$ de sucesso para o FCT 8 , quando eram esperados, no mínimo, $80 \%$. Ainda que o projeto esteja migrando da fase de concepção para a de planejamento dentro do seu ciclo de vida (SLEVIN; PINTO, 1987), esse dado demonstra, haver deficiências, em termos táticos, que precisam ser corrigidas.

A diferença entre os valores das modas e mínimos de cada fator crítico representa o cenário mais provável de sucesso que a implementação do projeto irá encontrar. Esse entendimento decorre de que a moda representa o valor de maior concordância entre todos os stakeholders dentro de cada grupo, enquanto o valor mínimo representa a maior insatisfação possível, ou seja, o pior cenário. Quanto mais se aproximarem os valores mínimos e as modas de $80 \%$, maior será a homogeneidade entre os stakeholders e, portanto, menor a probabilidade de conflito de interesse.

O comparativo entre os resultados referentes à moda e os valores mínimos de cada fator crítico avaliado pelos stakeholders está apresentado nas figuras 2, 3, 4 e 5. 
O G1, por possuir somente 1 (um) avaliador, apresenta valores iguais para moda e mínimo, o que compromete a análise da heterogeneidade dentro desse grupo. Mesmo assim, essa figura mostra claramente o desbalanceamento da gestão dos FCE 1 (Objetivos) e FCE 6 (Planejamento) comparativamente aos demais fatores.

Figura 2 - Comparação dos fatores críticos de sucesso apontados pelo $\mathrm{G} 1$, referentes aos resultados das modas e dos valores mínimos.

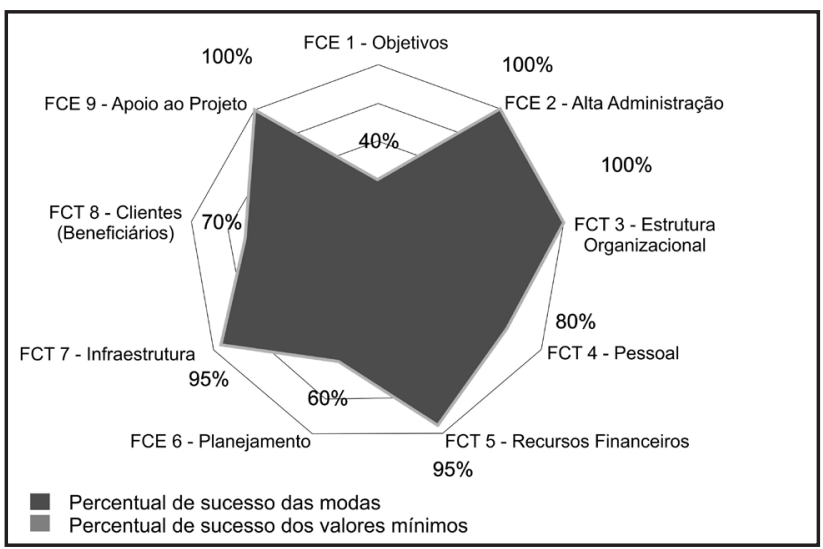

Fonte: $\mathrm{O}$ autor.

Em observação à Figura 3, percebe-se que o FCT 8 (Clientes) é o fator crítico mais heterogêneo para o G2, com uma diferença de $65 \%$. Outros fatores, como FCE 1 (Objetivos), FCE 2 (Alta Administração) e FCT 3 (Estrutura Organizacional), também precisam receber maior atenção, uma vez que a diferença entre os valores das modas e mínimos é superior a $45 \%$, ou seja, muito heterogêneo.

Figura 3 - Comparação dos fatores críticos de sucesso apontados pelo G2, referentes aos resultados das modas e dos valores mínimos.

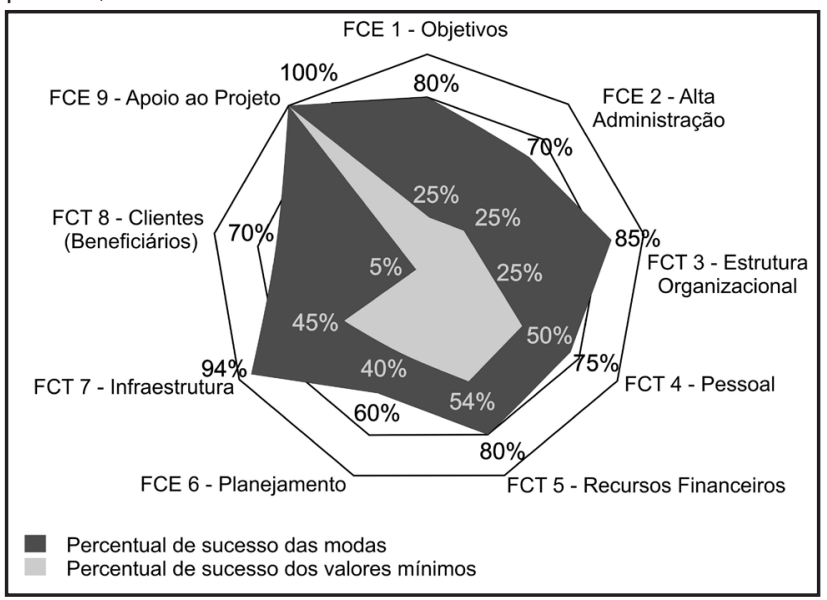

Fonte: $\mathrm{O}$ autor.

Nos dados observados nas Figuras 4 e 5, referentes, respectivamente, ao G3 e G4, o cenário é ainda pior. A heterogeneidade das respostas aponta para grandes diferenças em todos os fatores críticos estudados, a maior parte acima dos $50 \%$. O pior caso, novamente, é o do FCT 8 (Clientes), em que tanto a moda como o valor mínimo são muito baixos, e todos os envolvidos concordam com isso.
Figura 4 - Comparação dos fatores críticos de sucesso apontados pelo G3, referentes aos resultados das modas e dos valores mínimos

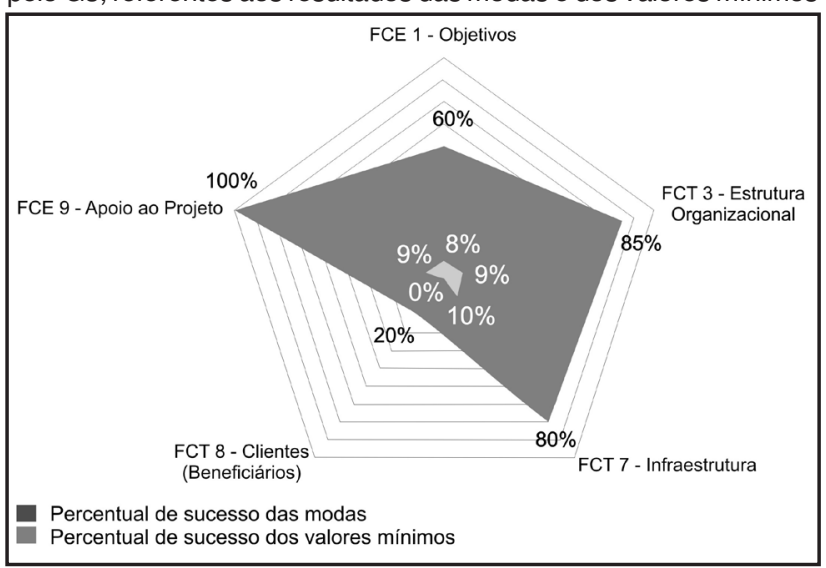

Fonte: O autor.

Figura 5 - Comparação dos fatores críticos de sucesso apontados pelo G4, referentes aos resultados das modas e dos valores mínimos.

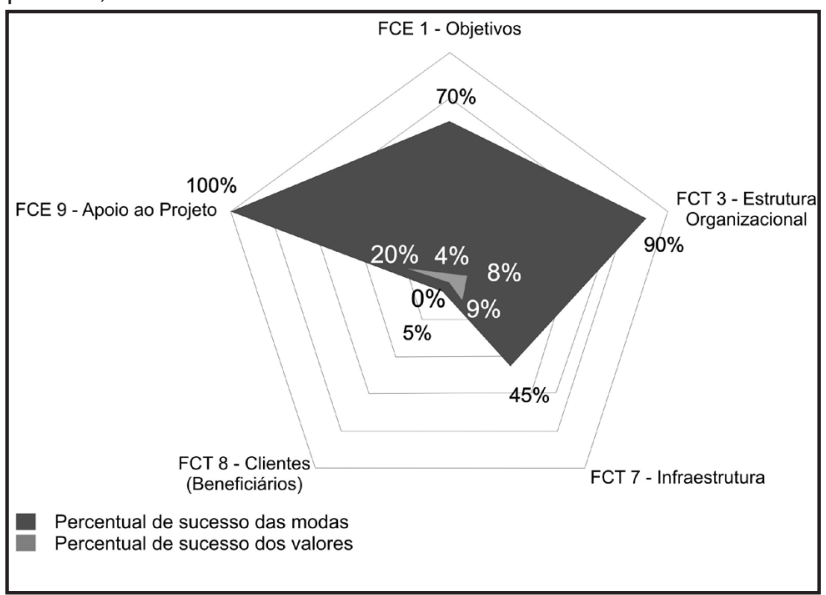

Fonte: $\mathrm{O}$ autor.

A análise desse cenário aponta que existem stakeholders claramente insatisfeitos nos G3 e G4. De acordo com a matriz de Qualman (1997), apresentada no Quadro 1, esses atores representam a classe dos que possuem grande interesse, porém pouco poder. A opinião deles não chega a inviabilizar o projeto, mas ainda assim é importante que se mantenham parceiros, pois apresentam ideias e ajudam com pequenas ações. Essa interpretação é confirmada pela análise dos resultados do FCE 9 (Apoio ao Projeto), que apresenta valores mínimos na casa dos $9 \%$ e $20 \%$, respectivamente, para os G3 e G4. Isso dá a entender que existem interessados que não coadunam com a criação do CDAer, provavelmente porque seus interesses não estejam sendo protegidos ou porque a comunicação do projeto não esteja sendo realizada de forma adequada.

Nesse sentido, cresce de importância a Matriz de Eficácia Estratégica e Tática, apresentada no Quadro 5 , uma vez que o cruzamento dos dados referentes às respostas de cada grupo aponta os aspectos que estão sendo menos ou mais eficazes e auxiliam na identificação dos erros potenciais de gestão. 
Quadro 5 - Matriz de eficácia entre os aspectos estratégicos e táticos.

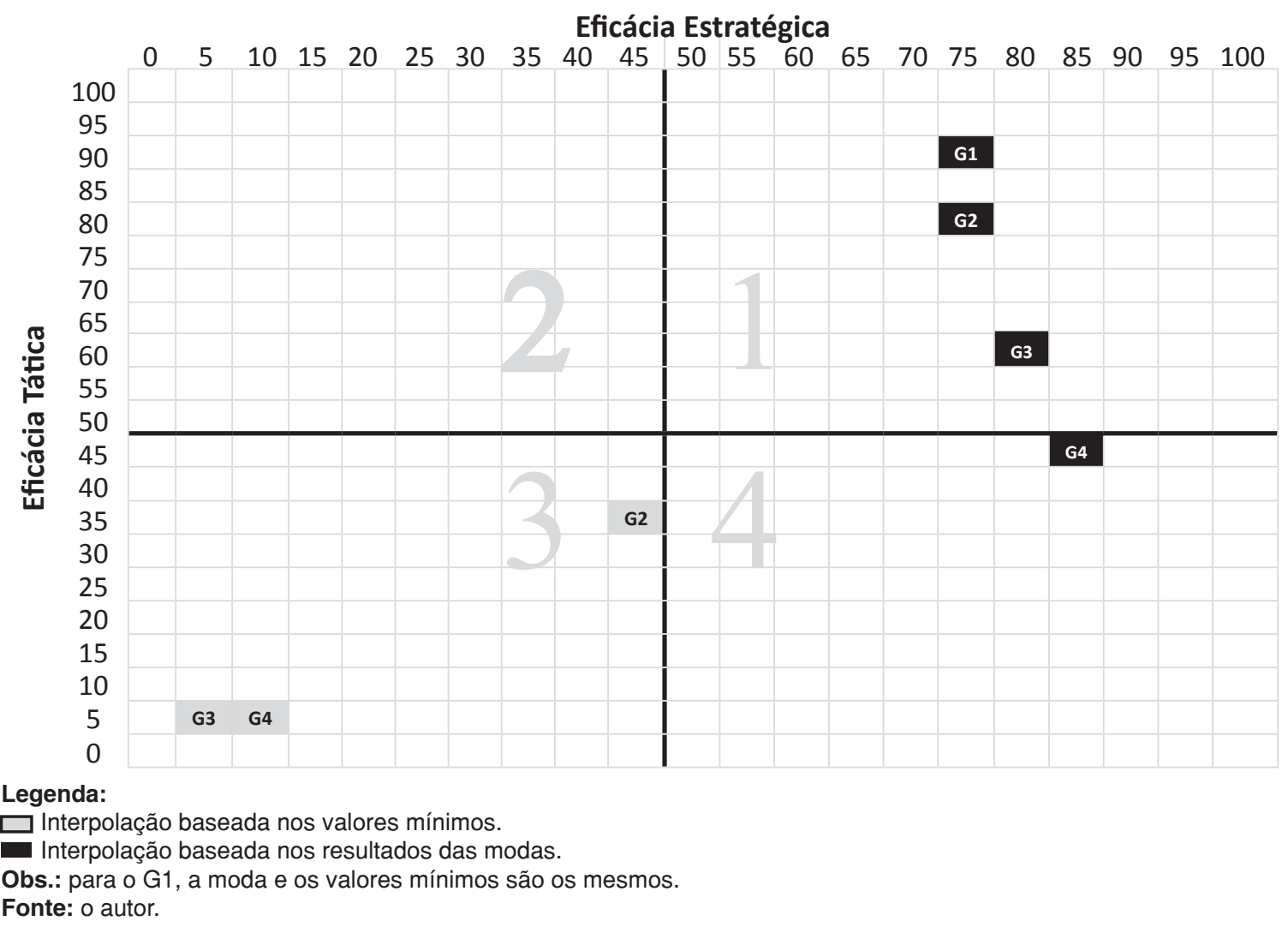

Pela análise do cruzamento dos dados referentes à moda, observa-se com clareza que, somados, os fatores críticos estratégicos (FCE) encontram-se inseridos em uma mesma faixa de percentual de sucesso entre $75 \%$ e $85 \%$ (intervalo de 10\%). No entanto o mesmo já não ocorre com os fatores críticos táticos (FCT), cuja faixa é bem mais ampla, variando de $45 \%$ a $95 \%$ (intervalo de $50 \%$ ).

Outra percepção imediata diz respeito ao quadrante em que se encontra cada grupo de stakeholders. Os G1, G2 e G3 estão no quadrante 1 que, de acordo com Slevin e Pinto (1997), apresentam grande potencial de implementação com sucesso. Já o G4 encontra-se no quadrante 4 , área de provável ocorrência dos erros do tipo I (projeto com baixa aceitação e baixa eficiência tática) e do tipo IV (baixa iniciativa para correção de rumo, ainda que se conheçam as falhas).

No estudo dos cruzamentos dos dados referentes aos valores mínimos, observa-se que o projeto corre grande risco de não ser implementado com sucesso, pois as respostas de 3 (três) grupos estudados encontramse presentes no quadrante 3 . Nesse caso, conforme apontam Slevin e Pinto (1987), além dos erros do tipo I e do tipo IV, deve-se atentar também para os do tipo II (empreender uma ação que não deveria ter sido adotada) e do tipo III (impacto colateral de uma ação corretiva, empregada para a solução de um determinado problema, mas que afeta outro).

Tais constatações são importantes e, ainda que aparentemente apresentem um viés negativo, o caso não está perdido. Rabechini (2007), adotando a mesma metodologia, cita um estudo realizado em uma empresa de agronegócio brasileira, em que os resultados foram bastante similares. O fator crítico Alta Administração foi um dos que recebeu as melhores pontuações, enquanto que os fatores Clientes e Comunicações necessitaram de maior atenção e receberam recomendações que culminaram em um redirecionamento gerencial do projeto. Nesses casos, o autor refere que há possibilidades factíveis de intervenção por parte dos gestores do projeto.

\section{CONCLUSÃO}

Este estudo teve como objetivo analisar de que forma os fatores críticos de sucesso, na ótica dos stakeholders, impactam na eficácia do projeto de implantação do CDAer.

A metodologia empregada propiciou investigar que os fatores críticos de sucesso, para a maior parte dos stakeholders do G1, G2 e G3, estão atendendo ao que se espera do projeto e que o mesmo apresenta uma eficácia estratégica maior que tática. O estudo também mostrou a existência de atores importantes (G4) não satisfeitos, pois o projeto carece de uma adequada estratégia de comunicação e de engajamento desses atores no processo. A análise dos valores mínimos também mostrou os tipos de erros potenciais do projeto, apresentando, ainda, o problema da heterogeneidade de opinião dos stakeholders.

Algumas lições são possíveis de serem derivadas desse estudo. A primeira delas é o entendimento de que 
uma gestão distante dos principais interessados gera insegurança e acarreta uma redução do apoio para a condução das atividades necessárias. A segunda infere que a conscientização e o apoio dos principais atores envolvidos devem ser fator preponderante na estruturação da proposta de criação do CDAer, desde o seu início. Por fim, a terceira infere que o projeto deve apresentar um claro diagnóstico de seus problemas, principalmente dos relacionados aos clientes, ao pessoal, aos recursos financeiros e à estrutura organizacional, respeitando-se o balanceamento estratégicotático da proposta, desde o começo.

Diante dessas lições, surgem algumas recomendações que podem ser adotadas para a correção dos rumos do projeto. Destaca-se, entre elas, a necessidade de desenvolver-se um plano de comunicação, com vistas à melhoria da troca de informações entre os gestores e os diferentes grupos de stakeholders.

Outra sugestão é de que deve ser preparado e definido um processo de suporte aos clientes e beneficiários do CDAer, procurando-se envolvêlos no projeto e aprimorando-se o escopo do plano de implementação elaborado. Associa-se, ainda, a necessidade de identificação das razões que levaram alguns stakeholders a não apoiarem a criação do CDAer e, dessa forma, elaborar-se um plano de contingências que assegure um redirecionamento adequado das ações a serem implementadas.

Como mais uma recomendação, propõe-se aumentar a eficácia tática do projeto, mapeando-se e detalhando-se as funções do pessoal e os recursos que serão empregados no CDAer. Por fim, ainda que a análise das dados do G1 tenha sido realizada sobre as respostas de somente 1 (um) avaliador, deve-se considerar que esse grupo é composto pelos mais poderosos stakeholders, visto que são os responsáveis pelas decisões finais relacionadas ao projeto. Dessa forma, a aproximação e a busca por orientação desses atores deve ser uma constante durante todo o processo.

\section{REFERÊNCIAS}

BRASIL. Comando da Aeronáutica. Comissão de Desportos da Aeronáutica. Proposta de criação do Centro de Desportos da Aeronáutica (CDAer). Ofício no 10/VP/614, de 17/03/2015. Rio de Janeiro, 2015.

FREEMAN, R.E. Strategic management: A stakeholder approach. Boston: Pitman, 1984.

GOLDSCHIMIDT, A. Stakeholders: como interagir com tantos públicos diferentes. Revista RETS, 2005. Disponível em: <https://www.google.com.br/url?sa=t\&rct=j $\& q=\& e s r c=s \&$ source $=$ web\& $c d=2 \&$ ved $=0$ CCUQFjAB\&url= http\%3A\%2F\%2Fwww.novosolhos.com.br\%2Fdownload. php\%3Fextensa0\%3Drtf\%26original\%3DStakeholde rs\%2520-\%2520\%2520Partes\%2520Interessadas\% 2520RETS\%2520ago2005.rt\%26servidor\%3Darq material\%2F59_58.rtf\&ei=H0zYU4SQLIfhsATOioKwDA\& usg=AFQjCNE901K7sZzEWXbTQ36v0KJ8pdcLaA\&sig2 =Y-o7eMV85hacis6tXENabg>. Acesso em: 26 jul. 2014.

MARCONI, M. A; LAKATOS, E. M. Fundamentação da metodologia científica. 5.ed. São Paulo: Atlas, 2003. 311p.

MOTTA, J. R. G. O negócio das arenas: profissionalismo esportivo, cultura e entretenimento. Future Studies Researsh Journal. São Paulo, v. 4, n. 2, p. 21-48, jul./dez. 2012.

PINTO, J. K.; SLEVIN, D.P. Critical success factors in effective project implementation. Sloan Management Review, 1987. Disponível em: <http://gspa.grade. nida.ac.th/pdf/PA\%20780\%20(Pakorn)/8.Critical\%20 Success\%20Factors\%20in\%20Effective\%20 Project\%20Implementati.pdf>. Acesso em: 24 jul. 2014.
QUALMAN, A. Note on stakeholder analysis. NGO Connect, 1997. Disponível em:<http://www. ngoconnect.net/documents/592341/749044/A+Note+ on+Stakeholder+Analysis>. Acesso em: 28 jul. 2014.

RABECHINI JR, R. O gerente de projetos na empresa. 2. ed. São Paulo: Atlas, 2007. 210p.

ROBINSON et al. Organising an Olympic Sport Organization. In: CAMY J.; ROBINSON, L. (Org). Managing Olympic Sports Organisations. Lausanne: Olympic Solidarity, p. 1-60, 2007.

ROCHA, C. M; BASTOS, F. C. Gestão do esporte: definindo a área. Rev. Bras. Educ. Fís. Esporte. São Paulo, v. 25, p. 91-103, dez. 2011.

SANTOS, F. R. O emprego da análise de stakeholders em um plano estratégico para a gestão da mobilidade sustentável: estudo de caso do campus da Universidade de Brasília. 2008. 99 f. Dissertação (Mestrado em Transportes) - Departamento de Engenharia Civil e Ambiental, Universidade de Brasília, Brasília, 2008.

SLEVIN, D. P.; PINTO, J.K. Balancing strategy and tatics in project implementation. Sloan Management Review, v. 29, n. 6, p. 33-41, 1987.

TOLEDO, J. R. Campeonato do índice de confiança social: Forças Armadas continuam do G4 e partidos seguem firme na lanterna. Forças Terrestres. Rio de Janeiro, Ago. 2013. Disponível em:<http://www. forte.jor.br/2013/08/01/campeonato-do-indice-deconfianca-social-forcas-armadas-continuam-no-g4e-partidos-seguem-firmes-na-lanterna/>. Acesso em: 27 jul. 2014. 